\title{
Model-Based Contract Design for Low Energy Waste Heat Contracts: The Route to Pricing
}

\author{
Edward Wheatcroft ${ }^{1, *}$, , Henry P. Wynn ${ }^{1,2}$, Victoria Volodina ${ }^{2}$, Chris J. Dent ${ }^{2,3}$ and Kristina Lygnerud ${ }^{4}$ \\ 1 Department of Statistics, London School of Economics, London WC2A 2AE, UK; H.Wynn@lse.ac.uk \\ 2 Alan Turing Institute, 96 Euston Rd, London NW1 2DB, UK; vvolodina@turing.ac.uk (V.V.); \\ chris.dent@ed.ac.uk (C.J.D.) \\ 3 School of Mathematics, University of Edinburgh, Edinburgh EH9 3JZ, UK \\ 4 IVL Swedish Environmental Research Institute, 41133 Göteborg, Sweden; kristina.lygnerud@ivl.se \\ * Correspondence: e.d.wheatcroft@lse.ac.uk
}

check for updates

Citation: Wheatcroft, E.; Wynn, H.P.; Volodina, V.; Dent, C.J.; Lygnerud, K. Model-Based Contract Design for Low Energy Waste Heat Contracts: The Route to Pricing. Energies 2021, 14, 3614. https://doi.org/10.3390/ en14123614

Academic Editor: Antonio Rosato

Received: 22 May 2021

Accepted: 14 June 2021

Published: 17 June 2021

Publisher's Note: MDPI stays neutral with regard to jurisdictional claims in published maps and institutional affiliations.

Copyright: (C) 2021 by the authors Licensee MDPI, Basel, Switzerland. This article is an open access article distributed under the terms and conditions of the Creative Commons Attribution (CC BY) license (https:/ / creativecommons.org/licenses/by/ $4.0 /)$.

\begin{abstract}
Urban Waste Heat Recovery, heat recovery from low-temperature urban sources such as data centres and metro systems, has a great deal of potential in terms of meeting domestic and commercial heat demands whilst significantly reducing carbon emissions. Urban sources of heat are advantageous in that they tend to be close to areas of high heat demand and are therefore highly suitable as inputs to existing and newly constructed district heating networks. This paper has two main focuses. Firstly, the issue of efficiency in waste heat recovery is addressed with a focus on Technical, Economic, Social, and Environmental (TESE) efficiencies, which we consider should be given equal consideration. Secondly, we address the question of contractual efficiency and argue that contracts should be underpinned by mathematical modelling. We then focus on the contractual relationship between the owner of the waste heat and the district heating operator and consider the question of waste heat pricing. We suggest a profit sharing approach in which the price per unit of waste heat is allowed to vary according to important aspects such as demand and the electricity price. A demonstration of this approach is presented using a simple model of a waste heat recovery system that extracts heat from a data centre in Brunswick, Germany.
\end{abstract}

Keywords: district heating and cooling; urban waste heat recovery; data centres; contracts; lowtemperature; excess heat

\section{Introduction}

There has been an accumulation of experience with district heating and cooling over the last ten years. Although countries like Sweden had already been at the forefront of development in this area, it quickly developed more widely following the success of the EU Celsius project and more specialized projects such as those focusing on low-temperature waste heat [1,2]. These initiatives can be considered as part of, or spin offs from, the EU Smart Cities programme [3] on the one hand and an increasing concern for future energy production on the other.

Despite these advances, there can be no doubt that climate change is, or should be, at the top of all political agendas. There has been a radical acceleration of interest in District Heating and Cooling (DHC). The most direct reason is the advent of 2050 and 2030 zero net carbon agendas, as represented by the EU Green Deal [4] and Energy Master Plan [5]. These include scenarios in which the banning of gas will make existing gas-driven DHC no longer viable leading to a major switch towards heat pumps, almost entirely dependent on renewable electricity. The catch-all phrase the "energy transition" is used to describe the current era [6].

"Smart" programmes no longer deserve the name solely on technical grounds such as the extensive use of digital technology. Objectives must be technical, economic, social and environmental (TESE). Projects need to be technically efficient, economically viable, 
address social targets such as fuel poverty, and contribute to low or zero carbon and low pollution. In addition even the smaller projects, and, in some sense, especially the smaller district and community projects, may have multiple stakeholders. Although most DHC projects are driven by cities, there is an increasing number of public/private partnerships.

There are two well-documented impediments to the development of DHC: the need for very high standards of work on business cases to make projects bankable and the design of resilient local contracts. A focus of this paper is on the latter and we argue that contracts should be underpinned by modeling. Our message regarding this is simple: good contracts, as with good business models, need to be based on modeling. The consideration of multiple TESE objectives gives rise to a number of issues, covered by the paper: broader definitions of efficiency than purely technical, choices of Key Performance Indicator (KPI) for model inputs and outputs, different pricing models and the inclusion of sections in contracts to cover both the short and long term dynamics of projects. The ideas of resilience (robustness) against the vagaries of supply and demand, sometimes captured by scenarios, and their need to be understood and embedded in contracts, is at least one good reason for modelling.

Waste heat recovery initiatives usually require the involvement of multiple parties with relationships formalised in contracts. Most notably, the waste heat producer and the receiver are usually different stakeholders, each with their own objectives. On top of this, there are often other stakeholders involved such as local authorities, housing developers and consultants. Designing contracts can be a challenging and time-consuming process. One of the aims of this paper is to discuss the process of designing "efficient" contracts in waste heat recovery projects. The relationship between the waste heat owner and the energy company is of utmost importance and a key question regards the price to be paid for the waste heat. We present a profit sharing mechanism for determining the price of waste heat in which profits are shared between the producer and the energy company. The proportion of profit assigned to each party is then a matter for negotiation.

Profit-sharing should, in our opinion, be part of a more general ethos that contracts should be model-based, that is should be attached to heat/energy models which are widely used and widely available, but should also have economic, environmental and social components. Although not completely satisfactory, the last two of these often appear as constraints, for example achieving stated levels of carbon reduction and affordable prices to avoid fuel poverty. We believe that, as well as providing a robust pricing formula, profit sharing can be a conduit between this type of modeling and contracts.

The ideas in this paper come largely from the perspective of the Horizon $2020 \mathrm{EU}$ funded project ReUseHeat which aims to demonstrate the use of low-temperature heat sources as inputs to district heating networks [2]. The project involves four demonstrator sites, with three extracting heat from a Metro station, a hospital, and a data center, respectively and the other demonstrating a dashboard aimed at showing the benefits of waste heat recovery. One of the aims of the project is to provide guidance regarding contract design in low-temperature heat recovery and this work is a major aspect of the paper. The work has also been carried out under the Managing Uncertainty in Government Modelling (MUGM) project taking place at the Alan Turing Institute, London which aims to understand better the role of uncertainty quantification in modelling [7].

The paper is organized as follows. In Section 2, we describe relevant background methodologies. In Section 3, we define various types of efficiency and discuss their importance in the context of waste heat recovery projects. In Section 4, we discuss the importance of Key Performance Indicators (KPIs) in contract design. In Section 5, we discuss the various stakeholders of waste heat recovery. In Section 6, we define the profit sharing mechanism and, in Section 7, we demonstrate it using a model based on heat recovery from a data center. In Section 8, we discuss scenarios, giving a number of examples and discussing their impact both on KPIs and on the profit-sharing mechanism. Section 9 presents our conclusions. 


\section{Background Methodologies}

In this section, we discuss traditional methodologies related to the treatment of technical, economic, social and environmental (TESE) features of infrastructure projects. We then discuss each of these in terms of efficiency in Section 3.

\subsection{Externalities and the Coase Theorem}

It was recognized early in economics that the central parts of economic theory, particularly general equilibrium theory concerning supply and demand, were insufficient to cover the full realities of economic life. Externalities cover effects, good or bad, which are exterior to the main "equations". Negative externalities are very close to the military concept of collateral damage covered under rather ancient approaches to the ethics of war. These ideas of proportionality arise: roughly, collateral damage should not be greater than is proportional in some sense to the main objective. In Economics, the modelling of externalities was introduced by Ronald Coase in a theory which came to be known as the Coase Theorem [8]. Put simply, the theory says that, if externalities are properly measured and folded into transaction costs, the economic equilibrium is still possible. Not surprisingly it is often studied as a way of modeling the relationship between the public and private sectors, because the additional costs are often felt by the public at large. Pollution is a good example [8].

\subsection{Cost Benefit Analysis (CBA)}

Following on from the last section, we could say that CBA has been the principal way to recognize the totality of externalities arising from, particularly major, civil projects: roads, rail, air transport. It received early criticism because of its attempt to monitor all aspects of a project. It has been criticized for a number of other reasons: (i) the difficulty of pricing, establishing the value of the effect, including inflating the benefits, (ii) the failure to assess the uncertainty aspects and the future consequences of such failure, (iii) the hiding of trade-offs between the different effects. At the very least, CBA should encourage discussion of trade-offs between what may be incommensurate effects, such as the value of an ancient woodland versus a new motorway, in order to take a more multi-objective approach $[9,10]$.

\subsection{Social Value}

Although over a hundred years old, the concept of social value has been rediscovered over the last twenty years, [11,12]. In the UK, the Public Services (Social Value) Act 2012 enshrined some of the ideas in law relating to public sector contracts. The idea is similar to that of externalities and cost-benefit analysis. It tries to capture the effects of contracts that may not be part of the main contracts, by building in a statutory duty to consider particularly local communities which may be affected, and this recognition may take the form of creating additional, even compensatory, actions. Examples would be funding a community center or an environmental improvement. Social value is closely related to Company Social Responsibility (CSR), Social Return on Investment (SRI) and Business Ethics. If there is a strong message from the social value movement, it is that, unless companies take their general responsibilities to society seriously, governments are likely to build them into corporate governance rules, something which happened in the area of risk [11-13].

\subsection{Life Cycle Analysis (LCA) and the Circular Economy}

Perhaps the most effective methodology for auditing the external effects of investment has been Life Cycle Analysis (also Life Cycle Assessment, Life Cycle Inventory), which goes back to near the start of the modern environmental movement. There are two basic ideas: (i) a product, (operation, investment etc.) has a life cycle, (ii) there is an environmental impact at every stage, from mining minerals which are used to make the product to disposal at "end-of-life". Initially concentrating on environmental, that is biological, impact it now includes concepts such as carbon footprint, associated with climate change. A successful 
application led to the WEEE directives banning landfill at the end of the life of electrical goods [14]. This led to improvements in component and material re-use.

In the way that old ideas are often given a boost by a change of title, the "circular economy" is very similar to LCA but with perhaps a greater emphasis on completely closing the "life-cycle loop". An example of the failure to close the loop is in plastics for which a large proportion still goes to landfill, despite the good intentions of manufacturers [15].

\section{Efficiency}

We are familiar with the notion of efficiency from everyday life. We might learn that our car runs most efficiently at a speed of $50 \mathrm{~km}$ per hour, and that large cars are "gas guzzlers" in heavy traffic. We might surmise that big racing boats are built to operate well in the kind of winds which arise in races, but not so well in low winds. A small dinghy is designed to pick up speed quickly even when the wind is light. Wind turbines are turned off in high winds, implying they have zero efficiency in such circumstances.

From these everyday examples, we see two things: (i) efficiency must be clearly defined. For example, for a car, this might be the number of kilometers from a liter of petrol at $60 \mathrm{~km}$ per hour, and (ii) efficiency itself depends on other variables such as the design of the car, the speed at which it is traveling etc. From this discussion, we see that efficiency $E$ is some kind of ratio $E=\frac{\gamma}{Z}$ and that this ratio may depend on internal design variable $\theta$ and exogenous (input) variables $x$.

\subsection{TESE}

Our initial task is to give one or more definitions of efficiency for each of our categories. This initial separation gives each category the same moral status and we want to argue against the kind of thinking which places one category as an externality. In an era in which economic prerogatives can be said to dominate, one place this is found is in objectives such as the maximization of profit subject to achieving environmental standards. Given that the primary aim of many "green" projects is to reduce carbon emissions or reduce pollution, the use of environmental standards as a constraint rather than as an objective in its own right means that opportunities to make further progress in such areas might be missed. We, therefore, need separate definitions for each category.

\subsubsection{Technical and Productive Efficiency}

The technical and productive efficiencies of a process both refer to the ratio of the output and the input. Technical efficiency can be thought of as the ratio of actual and potential output produced for some given fixed level of input, whilst productive efficiency can be thought of as the ratio of actual and potential input required for some given level of output $[16,17]$.

In the context of heat recovery projects, when heat pumps are used, their technical and productive efficiency are of utmost importance. The Coefficient of Performance (COP) of a heat pump is the ratio of the units of heat provided and the units of electricity used to supply it [18]. The electricity needed to provide a given number of units of heat is closely related to productive efficiency and the heat provided by a given number of units of electricity the technical efficiency. Both are governed by the COP. The key benefit of waste heat recovery is that the $\mathrm{COP}$ is typically greater than one and therefore the number of units of heat supplied is greater than the number that would be generated using the electricity directly (electricity is usually considered 100 percent efficient in producing heat and therefore one unit of heat is produced per unit of electricity).

The choice of heat pump is a key question in heat recovery projects. Heat demand is highly seasonal and thus a decision often has to be made as to whether to supply the baseload (i.e., demand that is present all year), the full heat demand, or something in between. If the full heat demand is not supplied by waste heat, an alternative such as a Combined Heat and Power (CHP) unit is required to meet the rest of the demand. The seasonality of heat demand, therefore, creates a trade-off. If the heat pump is able 
to supply year-round demand for heat, it will have an unused capacity for much of the year. On the other hand, a heat pump that is only able to supply the baseload may not make full use of the waste heat available. It is also worth noting that seasonality in the temperature of the waste heat will create seasonality in the COP. Generally, the bigger the difference between the temperature of the waste heat and the supplied heat, the lower the COP. The overall technical and productive efficiency may therefore be optimized by reducing the heat provided in the winter months. This, of course, may be undesirable and thus it may be useful to favor technical and productive efficiency subject to achieving other types of efficiency.

A high COP is desirable in waste heat recovery projects and the values that can be achieved have been investigated by a number of authors in the academic literature. Nyers, for example, presents a system for the recovery of heat from wastewater and it is suggested that a COP of around 6 may be possible [19]. Hepbasli et al. carry out a review of the $\mathrm{COP}$ of heat pumps used alongside wastewater treatment processes and values ranging from 1.77 to 10.63 are found, demonstrating the importance of local aspects in determining efficiency [20]. Deymi-Dashtebayaz et al. assess the COP values of heat pumps used for heat recovery from data centers and find that high values are possible, with the choice of refrigerant being a key factor [21]. The COP of heat recovery from wastewater in a metro station in Glasgow is investigated by Ninikas et al. and a time-averaged value of 2.5 is estimated [22].

\subsubsection{Economic (Pareto) Efficiency}

In the context of microeconomics, Pareto efficiency is achieved when no action can be taken to improve the position of any actor without negatively impacting another [23]. A corollary of Pareto efficiency is that the overall economic benefit is maximized. Consider, for example, an action in which one actor's economic benefit could be increased with a cost of reducing another's by some smaller amount. This situation would not be Pareto-efficient because the former could simply compensate the latter for their loss.

\subsubsection{Environmental and Social Efficiency}

Traditionally, economics has dealt with social and environmental effects by considering them 'externalities'. The idea is that production often has negative environmental and social effects. Environmental and social efficiency occurs when the overall cost to society is assigned to the producer.

The now traditional way to build a social element into the more general economic theory is with a welfare function [24]. This needs individual utilities to be combined in some way to give a societal measure of welfare. It has the usual dichotomy between (i) the raw utilitarian approach, that is maximize the average (total) welfare, and (ii) maximin: maximizing the welfare of the worst off. Alongside these are general issues such as equity (equality), social deprivation and social exclusion.

\subsection{Contractual Efficiency}

Contracts formalize relationships between parties, cementing rights and responsibilities in a legally binding fashion. Negotiating and writing contracts, however, is a time-consuming, and often costly, process. Hiring legal experts can be expensive and there is an opportunity cost in preparing for and participating in negotiations. Some of these costs can be significantly reduced when previously agreed contracts or specimen contracts can be referred to. In general, the more detailed the contract, the higher the costs involved. Contract theory considers the 'completeness' of a contract [25]. A contract is 'complete' if it includes every possible eventuality, removing the need for disputes. It is widely accepted that complete contracts are unattainable in practice and therefore contracts have varying degrees of 'incompleteness'. It is clear that there is a trade-off between the completeness of a contract and the costs involved in negotiating it. This trade-off is nicely described by Crocker and Reynolds [26] who argue that 
"Agents are confronted with a trade-off between the ex ante costs of crafting more complete agreements and the ex post inefficiencies associated with less exhaustive arrangements."

If contracts are necessarily incomplete, it is inevitable that some eventualities will not be covered. This is a risk to the involved parties because uncontracted events may lead to disputes and unpredictable outcomes. In light of this, the parties must prioritize the most important aspects of an arrangement. This usually means covering those eventualities that pose the biggest risk, i.e., that have a high probability and/or a high cost. There is then likely to be significant diminishing returns once the most important aspects are covered.

The above discussion applies to individual contractual arrangements but the argument can be extended to the wider context of a project in which multiple contractual arrangements are required. Increasing the number of involved parties in a project usually increases the number of contractual arrangements required and this comes at an increased cost. The trade off one must consider is then the increased cost of including an extra partner and the value in doing so. We consider a contractual arrangement to be efficient if it strikes the right balance between the 'completeness' of the contract and the cost of negotiations.

Contractual efficiency in waste heat recovery is not well-covered in the academic literature. However, the issue was considered by Lygnerud et al. who identify key factors for achieving contractual efficiency [27]. These are listed and described below.

1. Ensure that all parties are incentivized to carry out their obligations and continue with the arrangement.

2. Ensure that communication channels are kept open.

3. Clearly specify when renegotiation should take place.

4. Include mitigation clauses.

5. Keep the contract simple where possible.

In addition to the above, we suggest the following approaches to help achieve improved contractual efficiency:

1. Focus on highest risk aspects first.

2. Achieve greater symmetry of information and communication between parties.

3. Understand the risk of excluding clauses.

4. Clarify the definitions of KPIs.

5. Carry out effective modeling before negotiation takes place.

6. Ensure that contracts are monitored.

7. Optimise design and operations.

8. Use standard contract templates, where possible.

9. Reduce the number of required contractual arrangements.

10. Build close relationships between partners to reduce incentives to gain an advantage by entering into a dispute.

\subsection{Contract Guarantees and Service Level Agreements}

Several terms capture the inclusion of energy efficiency into contracts. Energy Performance Contracts (EPC) are standard in areas such as the supply of energy to buildings. Energy Efficiency is very closely related to this and the term 'Efficiency Performance' is used more widely. The most common form in which performance and efficiency are written into contracts is guarantees, sometimes named 'Service Level Agreements' (SLA), combined with scope for renegotiation in the case of failure to achieve the guaranteed, or a new guaranteed, level. Insurance against failure may be mandated in some cases and the technical term "efficacy insurance" is used to describe failure which may lead, for example, to damage to a third party, such as the failure of a water sprinkler for a fire.

\section{Contract Related KPIs}

There is no escape from trade-offs between the different types of efficiencies. The most economically efficient configuration may not be the most environmental or socially efficient 
if the lowest cost option produces high carbon emissions and/or pollution. The type of heat pump that maximizes technical efficiency may not be the most economically efficient, or even environmentally efficient, if the money saved from buying a less efficient heat pump could be put to better use. Despite this, from a methodological point of view, we favor approaches that retain a multi-objective flavor, rather than a reduction to a single objective which is likely to be financial. Taking this approach is one reason for the importance of clear specification, and understanding, of KPIs.

In general, we argue that important concerns related to efficiencies and resilience should be represented in technical, economic, social and environmental KPIs and that these KPIs should be represented in contracts. Effective modeling should underpin all of these where possible. On the ReUseHeat project, KPIs from each of these four areas were defined early on and are being monitored throughout the project. Technical KPIs include values such as the Coefficient of Performance (COP) of the heat pump and primary energy savings (kW/h). Financial KPIs such as the Return On Investment (ROI), Internal Rate of Return (IRR) and the payback period are all considered to be important to the viability of the projects. Other financial KPIs specific to heating are included such as the levelized cost of heat. Environmental KPIs are considered to be of great importance and include, for example, greenhouse gas emissions per unit of heat supplied (reducing this number is a key aim in all cases). Social KPIs are more difficult to define and monitor but, in ReUseHeat, include the degree of satisfaction among customers, comfort levels and attitudes expressed on social media.

\section{Stakeholders}

Waste heat recovery projects often have a wide range of stakeholders, some of whom are directly involved and others who are part of the wider community context. The former category includes stakeholders such as the waste heat owner, the energy company and the end-user. Here is a list for the latter category:

International. Due to climate change, every project on waste heat contributes to international commitments. This may be legal, part of an involvement in a supply chain or both.

National. Automatically, there are national stakeholders, for example in terms of funding, taxation or national policy. An example of this would be those interested in reducing fuel poverty.

Local and community. Again these arise automatically, for example in the planning process as part of electoral democracy or via more informal local consultation. It is likely that, as climate change action by government increases, the requirement to involve local communities will increase and various forms of "deliberative democracy" may flourish. A successful example of this is a dashboard developed as part of the ReUseHeat project in Toulon, France, in which users are able to visualize the benefits of waste heat recovery from seawater [28].

End-user. Although we are principally interested here in the immediate customer, the end-user is part of the system and generates demand, and may be featured in social objectives and objectives related to price. Care has to be taken to distinguish the end-user, that is the tenant paying rent, the leaseholder, who owns a long lease but may also pay the service charge which covers heating and cooling, and the owner/occupier. It is widely acknowledged that the relationship with the end-user is critical, particularly because of the newness of the systems, but also as part of general customer awareness and consumer relations. This affects contracts because of service level agreements, customer charters and so on.

\section{Materials and Methods}

By far, the most important contractual arrangement in waste heat recovery is between the waste heat supplier and the stakeholder to whom the heat is supplied, the heat receiver. The former may, for example, be a data centre, a metro operator, or a hospital such as those 
involved in the ReUseHeat project [2]. The latter may be a city, a Special Purpose Vehicle (SPV) set up specifically for providing DHC, or an energy company. Whilst there is often a need for other contractual arrangements, it is useful to focus upon this relationship because (i) a contract of this kind will always be necessary if the waste heat supplier and receiver are different stakeholders, (ii) the success of the project usually hinges on this relationship being maintained and (iii) this relationship presents novel challenges, not least the price paid (if any) for the waste heat.

There are many examples of formulae for the price of waste heat and these vary in complexity. In all cases, conditions for payment should be laid out clearly and unambiguously. Some examples of pricing formulae are given below:

1. Waste heat is provided for free.

2. A fixed weekly/monthly/annual fee is paid subject to conditions on quality and consistency of supply.

3. A fixed price per unit of heat is paid subject to temperature conditions.

4. A combination of fixed and variable payments are made.

5. Heat is purchased only under certain seasonal or weather conditions (these conditions should be clearly and unambiguously laid out).

A number of papers have considered the issue of pricing in waste heat contracts. Wynn, Wheatcroft and Lygnerud present the results of a set of interviews with stakeholders, in which some of the discussion focused on pricing [29]. One German waste heat owner revealed that the price of waste heat is based on a calculation of factors such as heat flow and temperature levels. Two Swedish waste heat owners stated that they were given a price list from the DH Company. One example in which the price list is made public is that of the Finnish energy company Fortum which publishes waste heat purchase prices for its operations in parts of Finland. The prices depend on both the weather and on whether the heat is sold to the supply or the return side of the network [30]. According to Wahlroos et al., DH network operators tend to vary the price according to the outside temperature on the basis that, when the outside temperature is high, there is lower demand for heat [31].

A dynamic approach to waste heat pricing in which the price depends on end-user demand is suggested by Pärssinen, with the argument that, when demand is high, the price should be high and vice versa [32]. Syri et al. suggest a marginal cost-based approach to pricing in which the supplier is paid the marginal cost of alternative sources of heat with a premium subtracted to account for the energy company's costs [30]. The price of waste heat is, therefore, dependent on the cost of producing heat from other technologies which are subject to variations in factors such as supply and demand. This approach is taken by Pärssinen et al. in their investment analysis in which they argue that pricing of waste heat is a crucial factor in terms of the profitability of waste heat recovery projects [32].

In this section, we propose a simple profit-sharing mechanism for determining the price of waste heat, in which, during negotiations, both parties agree to receive a fixed proportion of the overall profit from the waste heat recovery. The price per unit of waste heat is then the mechanism by which this profit sharing is achieved. Here, we describe the profit-sharing mechanism, discuss its advantages, and provide a simple example to demonstrate how it works in practice.

Over a given period of time, let $\operatorname{Prof}_{h s}$ and $\operatorname{Prof}_{e c}$ be the net profit from the waste heat recovery for the heat supplier and the energy company, respectively (noting that these can be positive or negative). The proportion of the overall profit that goes to the heat supplier is given by

$$
\alpha=\frac{\operatorname{Prof}_{h s}}{\operatorname{Prof}_{h s}+\operatorname{Prof}_{e c}} .
$$

The values of Prof $f_{h s}$ and Prof $f_{e c}$ are determined by the following quantities:

$P e$-Price paid by the end-user per unit of heat.

$P w$-Price paid by the energy company to the waste heat supplier per unit of waste heat.

C-Coefficient of performance of the heat pump. 
$D$-Units of end-user demand supplied by the waste heat.

$E$-Price per unit of electricity for running the heat pump.

$F_{e c}$-Fixed costs for the energy company.

$V_{e c}$-Cost per unit of waste heat for the energy company (excluding the price of waste heat and electricity).

$F_{h s}$-Fixed costs for the heat supplier.

$V_{h s}$-Cost to the heat supplier per unit of waste heat supplied.

$C_{h s}$-Value of cooling per unit of waste heat supplied by the waste heat supplier.

The overall profit for the energy company is determined by the following Equation:

$$
\operatorname{Prof}_{e c}=D\left(P e-P w-V_{h s}\right)-(D / C) E-F_{e c} .
$$

The first term in the formula represents the net gain from recovering heat and supplying it to the end-user, excluding the cost of electricity. The second term reflects the cost of the electricity required to power the heat pump, whilst the third term represents fixed costs that do not depend on the number of units supplied. The overall profit for the heat supplier is determined by

$$
\operatorname{Prof}_{h s}=\left(P w+C_{h s}-V_{h s}\right) D-F_{h s} .
$$

The first term represents the net gain from units of waste heat sold, whilst the second represents its fixed costs. Note that, for both parties, the profit depends directly on Pw. Here, we propose that a fixed $\alpha$ is agreed in contract negotiations and the price of waste heat $P w$ is adjusted to ensure this value is satisfied. To obtain an expression for the price of waste heat, we can solve Equation (1) with respect to $P w$, obtaining

$$
P w=\alpha\left(P e-V_{e c}-\frac{E}{C}-\frac{F_{e c}}{D}\right)-(1-\alpha)\left(C_{h s}-V_{h s}-\frac{F_{h s}}{D}\right) .
$$

The equation is, in fact, intuitive since the price of waste heat is simply a weighted average of the non-adjusted profit (i.e., setting Pw to zero) of the energy company and that of the waste heat provider.

\subsection{Profit Sharing and Contract Negotiations}

The profit-sharing mechanism offers a simple approach to the pricing element of contract negotiation. The two parties must simply agree to the pricing formula and negotiate the value of $\alpha$. In practice, the agreed value of $\alpha$ will usually depend on the negotiating positions of the two parties. For example, if the energy company is in contact with another potential heat source owner, this may increase their negotiating power and they may be able to reduce $\alpha$ and therefore the cost it pays for waste heat. The parties may also negotiate on the basis of different levels of risk. If one party pays for the infrastructure, they may argue that their risk is higher and therefore they should receive a greater reward in return. Simple adjustments to the approach may also be made. For example, if the overall profit $\operatorname{Prof}_{h s}+\operatorname{Prof}_{e c}$ becomes negative, under the profit-sharing mechanism the value of $P w$ will also be negative, requiring the heat supplier to pay the energy company rather than vice versa. To avoid such a situation, the heat supplier might negotiate a 'floor' on the price. The results of simple modelling can be brought into negotiations, providing clear estimates of the influence of different values of $\alpha$ in different scenarios.

\subsection{Advantages and Disadvantages of Profit Sharing}

There are a number of advantages to the profit-sharing mechanism. Firstly, the approach provides robustness with respect to different scenarios. Consider, for example, a scenario in which subsidies are introduced for electricity used to power heat pumps for waste heat recovery. Given this sudden improvement in the profitability of the heat recovery, the heat supplier may demand a renegotiation for the price of waste heat, such that they 
receive a proportion of the increased financial benefit. Under the profit-sharing mechanism, however, the price of waste heat is automatically adjusted upwards to account for this change. In an alternative scenario in which competition from other technologies forces the energy company to lower its price to the end-user, the mechanism would automatically adjust the price of waste heat downwards, sharing the cost between the two parties.

A disadvantage of the mechanism is that, for competitive reasons, one or more parties may be unwilling to disclose the financial information needed for the pricing formula. Agreement to use this approach, therefore, requires a high-level of transparency.

\section{Results}

We consider the use of a simple model to demonstrate the profit-sharing mechanism. The model, details of which can be found in Appendix A, is built in GNU MathProg and represents a waste heat recovery system from a data center loosely based on a system under construction in Brunswick, Germany, which is a demonstrator site of the ReUseHeat project [2]. The data center will supply waste heat via a heat pump to a newly constructed district containing 400 housing units and a number of commercial units. The district will also be connected to the existing city-wide district heating network which is powered using a gas-fired combined heat and power (CHP) unit. Since the CHP is close to capacity for meeting current demand in the city, its capacity will need to be upgraded at a fixed cost. In Brunswick, the capacity of the heat pump has been chosen to meet only the baseload heat demand of the new district (a demand that is present all year such as hot water). Here, however, we consider a case in which a larger capacity heat pump is to be installed and is therefore also capable of meeting a proportion of seasonal demand. We also assume that the existing CHP is unable to provide the entire heat demand throughout the year. The size of the heat pump places a natural upper bound on the number of units of waste heat that can be supplied by the data center. We define a lower bound such that a minimum number of units must be supplied by the data center (this provides security to the data center and may be negotiated in the contract). We define demand profiles for each of the four seasons (Spring, Summer, Autumn and Winter), in which days are divided into two different time slices (day and night). We, therefore, assume that each time slice in each season (referred to as a 'time segment') has the same level of demand. Each time segment then has its own value of $P w$ which depends on $\alpha$. The model optimizes the proportion of end-user heat to be supplied by each source (data center or CHP), with respect to the energy company's overall costs of supplying it for each time segment. Since $\alpha$ itself impacts the costs of the energy company, an optimization process is performed for each considered value of $\alpha$ such that its value is taken into account during the process. This means that the value of $\alpha$ may impact the number of units of waste heat supplied by the data center. Details of the parameters for the profit-sharing mechanism are given in Table 1.

Table 1. Parameters for the Brunswick example.

\begin{tabular}{cc}
\hline Parameter & Value \\
\hline$P e(€ / \mathrm{MW})$ & 186 \\
$E(€ / \mathrm{MW})$ & 3 \\
$F_{e c}(€)$ & 51 \\
$V_{e c}(€ / \mathrm{MW})$ & 1 \\
$F_{h s}(€)$ & 0 \\
$V_{h s}(€ / \mathrm{MwH})$ & 0.1 \\
$C_{h s}(€ / \mathrm{MW})$ & 1 \\
\hline
\end{tabular}

The effect of $\alpha$ on $P w$ is demonstrated in Figure 1. As expected, as $\alpha$ is increased, the data center receives a higher price per unit of waste heat $P w$ since it is entitled to a larger proportion of the overall profit. Differences between seasons are explained by variations in the profit margin of the energy company. Since it is assumed that the fixed 
costs are evenly spread over the lifetime of the infrastructure, during the summer months the fixed costs per unit of end-user heat $\left(\frac{F_{e c}}{D}\right)$ are higher than for the other seasons, reducing the profit margin of the energy company and therefore the price P $w$. Note how, for most time segments, the value of $P w$ against $\alpha$ is not a straight line. This is because there is a threshold of $\alpha$ at which it becomes cheaper for the energy company to switch from using heat from the data center to heat from the CHP. To demonstrate the effect of this, the number of units of end-user heat supplied by the data center and the CHP for each time segment are shown for two values of $\alpha$ in Figure 2. When $\alpha=0$, it is cheaper for the energy company to purchase heat from the data center whilst, for $\alpha=0.3$, it is cheaper to use the entire available capacity of the CHP first. This demonstrates that, in some cases, it may be beneficial for the heat supplier to agree to a lower value of $\alpha$ but sell more units of waste heat as a result.
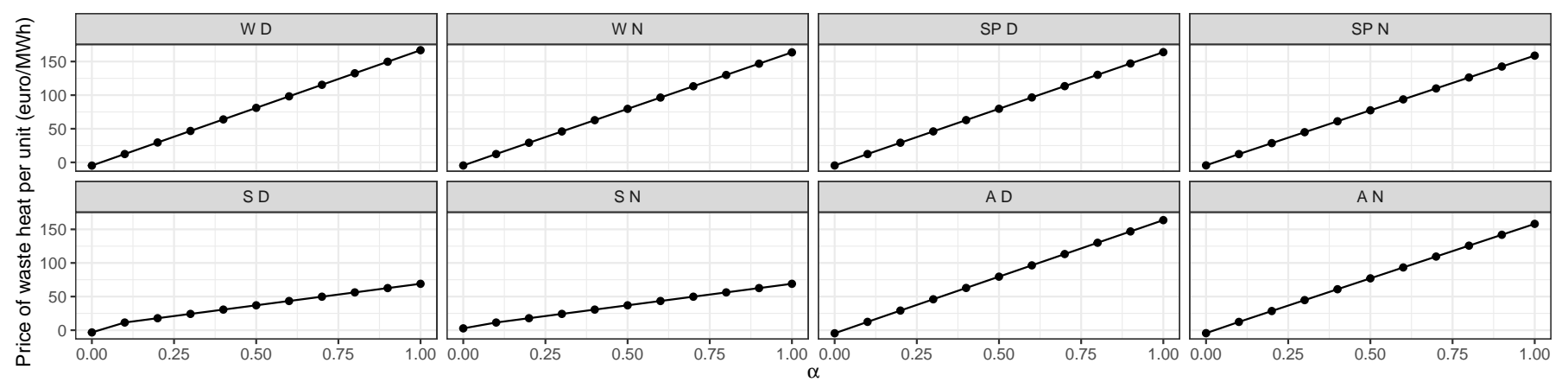

Figure 1. Price per unit of waste heat $P w$ as a function of $\alpha$ for each time segment.

(a)

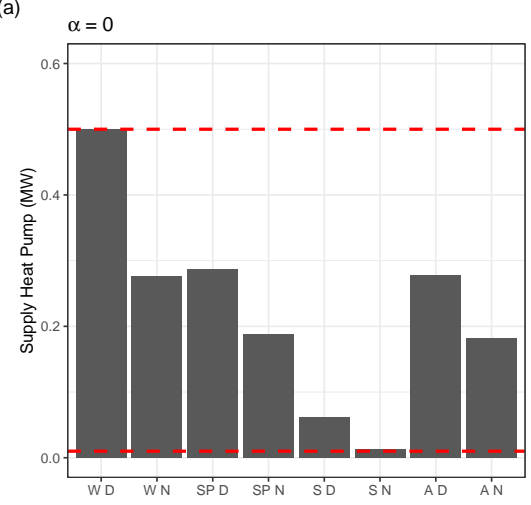

(c)

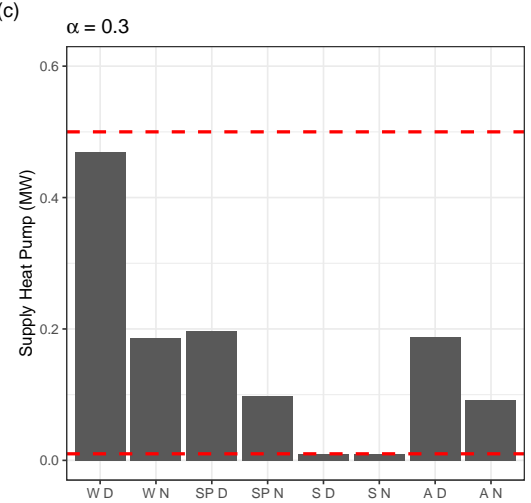

(b)

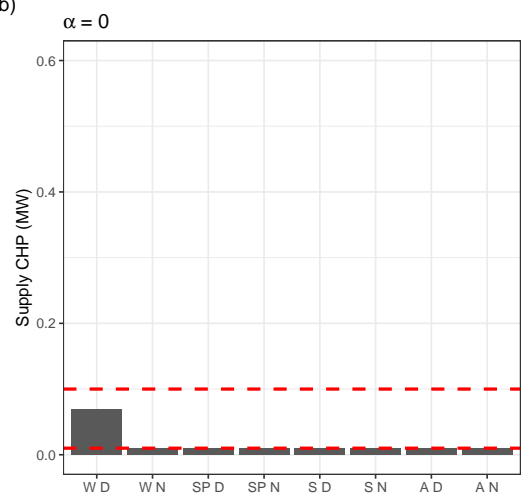

(d)

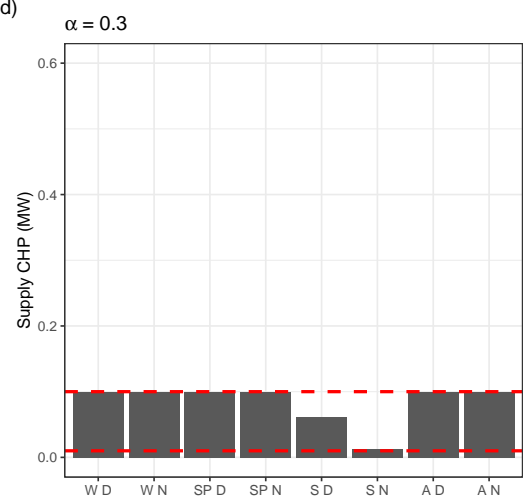

Figure 2. Units of end-user heat demand supplied by the data centre $(\mathbf{a}, \mathbf{c})$ and the CHP $(\mathbf{b}, \mathbf{d})$ in each time segment for $\alpha=0.3$ (upper panels) and $\alpha=0$ (lower panels). Red dashed lines denote the capacity constraints of each technology. 


\section{Contract-Related Scenarios in Heat Recovery}

It is useful to think of risk both in terms of large-scale scenarios and smaller-scale variations. The former is particularly relevant to waste heat recovery due to the fact that it is a relatively immature technology with little or no regulatory framework (and thus various scenarios as to how a framework might develop can be considered). There is also significant uncertainty regarding the extent to which governments will prioritize heat recovery for incentives and tax breaks. Scenarios can usually be assumed to be driven by external events such that the stakeholders can only react rather than control them.

Scenarios can have a significant impact on TESE efficiencies and, consequently, on contractual efficiency. The impacts of scenarios on heat recovery efficiencies can be positive or negative and it is useful to consider both in the context of waste heat pricing. Under many pricing schemes, contractual efficiency may be lost if there is a significant change in circumstances. The profit sharing mechanism, however, allows contracts to be resilient to many of these changes. Below, we define a number of scenarios for heat recovery and discuss how these relate to both the profit-sharing mechanism and to KPIs (denoted in italics).

1. Combined Heat and Power (CHP) phased out: CHP units are often used either to provide the proportion of heat not supplied by the heat recovery or as a backup supply. In this scenario, an alternative supply would need to cover the shortfall and this might be solved by ramping up waste heat recovery. Under the profit-sharing mechanism, economies of scale will increase the price of waste heat and the cost per unit of end-user heat. There is also likely to be a reduction in $\mathrm{CO}_{2}$ emissions per unit of heat supplied.

2. Increased insulation in buildings: This would reduce demand which, in turn, may reduce economies of scale. Under the profit-sharing mechanism, the cost per unit of end-user heat would therefore increase and, consequently, the price per unit of waste heat would decrease.

3. Significantly increased average temperatures due to climate change: This would likely reduce heat demand and therefore reduce economies of scale, increasing the cost per unit of end-user heat and reducing the price of waste heat.

4. Government subsidies for heat storage: This policy would aim to make it financially beneficial to invest in heat storage which would allow the heat pump to supply a greater proportion of end-user demand (due to reductions in the effect of seasonality). This would reduce the cost per unit of end-user heat and, since the profit is shared with the waste heat supplier, would increase the price of waste heat.

5. Change in law obligating waste heat owners to supply waste heat for free: This would remove the need for the energy company to pay the waste heat supplier and the profit-sharing mechanism would no longer be needed. This would reduce the cost per unit of end-user heat but increase the cooling costs for the waste heat supplier (if applicable).

6. Government support for alternative technologies (e.g., heat pumps, solar panels): If governments decide to invest in alternative sources such as solar and small scale air or ground source heat pumps, this may reduce demand for district heating and reduce economies of scale, increasing the cost per unit of end-user heat. Under the profit-sharing mechanism, this would reduce the price per unit of waste heat.

7. Subsidised electricity for heat pumps: This would reduce the cost per unit of end-user heat, increasing profits for the energy company which would result in an increase in the price of waste heat under the profit-sharing mechanism. If production is ramped up, this may lead to a reduction in $\mathrm{CO}_{2}$ emissions per unit of heat supplied as a lower proportion of heat demand is supplied by other sources such as CHP.

\section{Conclusions}

The paper makes the case for an emphasis on modeling as part of contract design for waste heat recovery projects. Although often small in the context of energy infrastructure development, waste heat recovery is relatively new and is rapidly increasing in importance. 
Waste heat recovery has a number of special features which need to be taken into account. Complexities include the differing properties of different waste heat source, connection to existing heat networks, multiple stakeholders (insofar as they are increasingly communitybased projects) and fluctuating public-private funding sources. After introductory sections giving a relevant background in contract-design, the paper focuses on the key issue of pricing. The newness of these contracts means that we are still in a period in which it is hard to establish standardized contracts. Pricing systems range from the waste heat being supplied for free to ambitious plans to establish a proper market in waste heat. This work can be seen as providing a framework in which, via a modelling core, schemes can be designed for sharing profits between the waste heat supplier and the purchaser. Our case study uses realistic KPIs for inputs and outputs and internal parameters based on the Brunswick demonstrator in the EU ReUseHeat project. One of the advantages of having a modeling platform is the ability to design contracts that are resilient to the local variation of inputs and, increasingly importantly, to more global scenarios driven by national and international decisions taken along the road to achieving 2050 net-zero carbon objectives.

Author Contributions: The contributions of each author were as follows: methodology, E.W., H.P.W. and V.V.; formal analysis, E.W., H.P.W. and V.V.; investigation, all authors; original draft preparation, E.W., H.P.W. and V.V.; writing — review and editing, all authors. All authors have read and agreed to the published version of the manuscript.

Funding: This work has been carried out with funding from the H2020 ReUseHeat project (grant number 767429) and Managing Uncertainty in Government Models (MUGM) at the Alan Turing Institute, London (project code R-EDI-002).

Conflicts of Interest: The authors declare no conflict of interest.

\section{Appendix A. Heat Model Specification}

The energy model presented in Section 7 is written in GNU MathProg, (Boston, MA., USA) [33] and is largely based on an implementation in OSeMOSYS (Open Source Energy Modelling System) [34]. The model computes the units of heat to be supplied by the CHP unit and the heat pump to minimise the cost to the energy company of meeting the demand in each time segment. This then determines the level of demand supplied by the heat pump and feeds into the profit sharing mechanism.

Define the following sets

- Time slices $\mathcal{T}$, index $t$, elements $\left\{1 \ldots n_{T}\right\}$. Time slices correspond to the division of calendar days. In our case, we divide each one into 'day' and 'night'.

- Seasons $\mathcal{S}$, index $s$, elements $\left\{1 \ldots n_{S}\right\}$. We consider 4 seasons: Spring, Summer, Autumn and Winter.

- Heat supply technologies $\mathcal{U}$, index $u$, elements $\left\{1 \ldots n_{U}\right\}$. In our example, $u=1$ and $u=2$ correspond to the Heat Pump and CHP, respectively.

Here, $n_{S}=4$ and $n_{T}=2$ such that there are a total of 8 time segments. It is assumed that each day within each season and time slice has the same level of demand, e.g., each winter night is treated the same.

We have the following variables:

$[\text { supply }]_{s t u}$ : heat supply from technology $u(\mathrm{MW})$.

[price_waste $]_{s t}$ : total price of waste heat paid by the energy company to the waste heat supplier in season $s$, time slice $t(€)$.

$[\mathrm{TVC}]_{s t}$ : total variable costs in season $s$ and time slice $t(€)$.

$[\mathrm{TFC}]_{s t}$ : total fixed costs in season $s$ and time slice $t(€)$.

$[\mathrm{TC}]_{s t}$ : total cost of supplying the end-user heat in season $s$ and time slice $t(€)$.

We have the following parameters:

$n_{s}^{\text {days }}:$ number of days in season $s$.

$n_{t}^{\text {hours: }}$ number of hours in time slice $t$.

$[\mathrm{dem}]_{s t}$ : demand in season $s$, time slice $t$, (MW). 
supply $y_{u}^{-}$: minimum supply from technology $u,(\mathrm{MW})$.

supply $u_{u}^{+}$: maximum supply from technology $u$ (MW)

[price_heat $]_{s t}$ : price of heat paid by the end-user in season $s$, time slice $t(€ / \mathrm{MW})$.

[val_cooling $]_{s t}$ : value of cooling in season $s$, time slice $t(€ / \mathrm{MW})$.

[fixed_cost $]_{s t u}$ : fixed costs for the energy company associated with technology $u$ in season $s$ and time slice $t(€)$.

$[\text { var_cost }]_{s t u}$ : variable cost per unit of heat supply from technology $u$ in season $s$ and time slice $t(€ / \mathrm{MW})$.

[fixed_costHS] $]_{s t}$ : fixed costs for the waste heat supplier in season $s$ and time slice $t(€)$.

$[\text { var_costHS }]_{s t}$ : variable cost per unit for the waste heat supplier in season $s$ and time slice

$t(€ / \mathrm{MW})$.

$\alpha$ : value of $\alpha$ in the profit sharing mechanism.

The model is defined by the following equations:

$$
\begin{gathered}
{[\text { price_waste }]_{s t}=\alpha\left([\text { price_heat }]_{s t}[\text { supply }]_{s t 1}-[\text { var_cost }]_{s t 1}[\text { supply }]_{s t 1}-[\text { fixed_cost }]_{s t 1}\right)} \\
-(1-\alpha)\left([\text { val_cooling }]_{s t}[\text { supply }]_{s t 1}-[\text { var_costHS }]_{s t}[\text { supply }]_{s t 1}-[\text { fixed_costHS }]_{s t}\right) \\
{[\mathrm{TVC}]_{s t}=[\text { price_waste }]_{s t}+[\text { supply }]_{s t 1}[\text { var_cost }]_{s t 1}+[\text { supply }]_{s t 2}[\text { var_cost }]_{s t 2}} \\
{[\mathrm{TFC}]_{s t}=[\text { fixed_cost }]_{s t 1}+[\text { fixed_cost }]_{s t 2}} \\
{[\mathrm{TC}]_{s t}=[\mathrm{TVC}]_{s t}+[\mathrm{TFC}]_{s t} .}
\end{gathered}
$$

The objective function to be minimised is

$$
\sum_{s t} n_{s}^{\text {days }} n_{s t}^{\text {hours }}[\mathrm{TC}]_{s t}
$$

subject to the following constraints:

$$
\begin{gathered}
{[\mathrm{dem}]_{s t}=\sum_{u}[\text { supply }]_{s t u}} \\
{[\text { supply }]_{u}^{-} \leq[\text {supply }]_{s t u} \leq[\text { supply }]_{u}^{+} .}
\end{gathered}
$$

The former constraint represents the Power balance and the latter ensures that the minimum and maximum allowed level of supply for each technology is maintained.

It is important to note that modelling should take into account all affected income streams for the energy company. For example, if the heat from the data centre replaces existing supply from the CHP unit, this will reduce the output from the CHP, and therefore may reduce economies of scale, increasing the cost per unit of supplying the rest of the city. This increase in costs should be included in the optimisation function. In our case, heat from the data centre is used to supply a newly constructed area of the city and therefore, rather than supply being switched from the CHP to the data centre, the heat demand is newly created. It is assumed here that the CHP is currently running at capacity and that an increase in capacity is required to supply the new area (at a fixed cost). Whilst there are economies of scale associated with increasing the number of CHP-supplied units to the new area (since the fixed cost is spread over more units), this does not affect the cost of supplying the rest of the city and therefore there is no need to include it in the optimisation function. We are aware of the importance of linking models such as ours to larger city wide or regional models and eventually national energy models but our objective is here is to increase the attractiveness of local contracts as prerequisites: effective components in larger systems.

\section{References}

1. Celsius. Celsius-Smart Cities. 2020. Available online: https://celsiuscity.eu/ (accessed on 30 January 2021).

2. ReUseHeat. ReUseHeat. 2021. Available online: https:/ / www.reuseheat.eu/ (accessed on 17 May 2021).

3. Smart Cities. Smart Cities. 2021. Available online: https://ec.europa.eu/info/eu-regional-and-urban-development/topics/ cities-and-urban-development/city-initiatives/smart-cities_en (accessed on 11 January 2021). 
4. European Union. A European Green Deal. 2021. Available online: https://ec.europa.eu/info/strategy/priorities-2019-2024/ european-green-deal_en (accessed on 11 January 2021).

5. High Level Group on Energy-Intensive Industries. Masterplan for a Competitive Transformation of EU Energy-Intensive Industries. Enabling a Climate-Neutral Circular Economy by 2050. 2019. Available online: https://op.europa.eu/en/publicationdetail/-/ publication/be308ba7-14da-11ea-8c1f-01aa75ed71a1 (accessed on 11 January 2021).

6. Eyl-Mazzega, M.A.; Mathieu, C. The European Union and the Energy Transition. In The Geopolitics of the Global Energy Transition; Springer: Berlin/Heidelberg, Germany, 2020; pp. 27-46.

7. MUGM. ReUseHeat. 2021. Available online: https://www.turing.ac.uk/research/research-projects/managing-uncertaintygovernment-modelling (accessed on 17 May 2021).

8. Farrell, J. Information and the Coase theorem. J. Econ. Perspect. 1987, 1, 113-129. [CrossRef]

9. Vincent, C.; Gumbel, E.A. Knowing the Price of Everything and the Value of Nothing; Emerald Group Publishing Limited: Bingley, UK, 1999.

10. Ackerman, F. Critique of cost-benefit analysis, and alternative approaches to decision-making. In Friends of the Earth England, Wales and Northern Ireland, London; 2008. Available online: http://frankackerman.com/publications/costbenefit/Critique_Cost_ Benefit_Analysis.pdf (accessed on 27 January 2021).

11. UK Government. Social Value Act: Information and Resources. Available online: https://www.gov.uk/government/publications/ social-value-act-information-and-resources/social-value-act-information-and-resources (accessed on 27 January 2021).

12. Mulgan, G. Measuring social value. Stanf. Soc. Innov. Rev. 2010, 8, 38-43.

13. Schumpeter, J. On the concept of social value. Q. J. Econ. 1909, 23, 213-232. [CrossRef]

14. European Commission. Additional Tools Waste Electrical and Electronic Equipment (WEEE). 2021. Available online: https: / / ec.europa.eu/environment/waste/weee/index_en.htm (accessed on 27 January 2021).

15. Ayres, R.U. Life cycle analysis: A critique. Resour. Conserv. Recycl. 1995, 14, 199-223. [CrossRef]

16. Färe, R.; Lovell, C.K. Measuring the technical efficiency of production. J. Econ. Theory 1978, 19, 150-162. [CrossRef]

17. Farrell, M.J. The measurement of productive efficiency. J. R. Stat. Soc. Ser. A 1957, 120, 253-281. [CrossRef]

18. Blanchard, C. Coefficient of performance for finite speed heat pump. J. Appl. Phys. 1980, 51, 2471-2472. [CrossRef]

19. Nyers, J. COP and economic analysis of the heat recovery from waste water using heat pumps. Acta Polytech. Hung. 2016 $13,135-154$.

20. Hepbasli, A.; Biyik, E.; Ekren, O.; Gunerhan, H.; Araz, M. A key review of wastewater source heat pump (WWSHP) systems. Energy Convers. Manag. 2014, 88, 700-722. [CrossRef]

21. Deymi-Dashtebayaz, M.; Valipour-Namanlo, S. Thermoeconomic and environmental feasibility of waste heat recovery of a data center using air source heat pump. J. Clean. Prod. 2019, 219, 117-126. [CrossRef]

22. Ninikas, K.; Hytiris, N.; Emmanuel, R.; Aaen, B. Recovery and Valorisation of Energy from Wastewater Using a Water Source Heat Pump at the Glasgow Subway: Potential for Similar Underground Environments. Resources 2019, 8, 169. [CrossRef]

23. Black, J.; Hashimzade, N.; Myles, G. A Dictionary of Economics; Oxford University Press: Oxford, UK, 2012 ; p. 301.

24. Coleman, J.S. The possibility of a social welfare function. Am. Econ. Rev. 1966, 56, 1105-1122.

25. Bolton, P.; Dewatripont, M. Contract Theory; MIT Press: Cambridge, MA, USA, 2005.

26. Crocker, K.J.; Reynolds, K.J. The efficiency of incomplete contracts: An empirical analysis of air force engine procurement. RAND J. Econ. 1993, 24, 126-146. [CrossRef]

27. Lygnerud, K.; Wheatcroft, E.; Wynn, H. Contracts, business models and barriers to investing in low temperature district heating projects. Appl. Sci. 2019, 9, 3142. [CrossRef]

28. ReUseHeat. ReUseHeat: Nice. 2020. Available online: https://www.reuseheat.eu/nice/ (accessed on 1 June 2021).

29. Wynn, H.; Wheatcroft, E.; Lygnerud, K. Efficient Contractual Forms and Business Models for Urban Waste Heat Recovery. In ReUseHeat Deliverable 2.3; 2019. Available online: https://www.reuseheat.eu/wp-content/uploads/2021/03/D2.3-UPDATED_20 210223.pdf (accessed on 1 June 2021).

30. Syri, S.; Mäkelä, H.; Rinne, S.; Wirgentius, N. Open district heating for Espoo city with marginal cost based pricing. In Proceedings of the 2015 12th International Conference on the European Energy Market (EEM), Lisbon, Portugal, 19-22 May 2015; pp. 1-5.

31. Wahlroos, M.; Pärssinen, M.; Rinne, S.; Syri, S.; Manner, J. Future views on waste heat utilization-Case of data centers in Northern Europe. Renew. Sustain. Energy Rev. 2018, 82, 1749-1764. [CrossRef]

32. Pärssinen, M.; Wahlroos, M.; Manner, J.; Syri, S. Waste heat from data centers: An investment analysis. Sustain. Cities Soc. 2019, 44, 428-444. [CrossRef]

33. Makhorin, A. Modeling language gnu mathprog. Relat. Tec. Mosc. Aviat. Inst. 2000, 63. Available online: http://www.cs.unb.ca/ bremner/docs/glpk/gmpl.pdf (accessed on 1 June 2021).

34. Howells, M.; Rogner, H.; Strachan, N.; Heaps, C.; Huntington, H.; Kypreos, S.; Hughes, A.; Silveira, S.; DeCarolis, J.; Bazillian, M.; et al. OSeMOSYS: The open source energy modeling system: an introduction to its ethos, structure and development. Energy Policy 2011, 39, 5850-5870. [CrossRef] 